\title{
A epidemia de HIV/Aids e a ação do Estado. Diferenças entre Brasil, África do Sul e Moçambique
}

\author{
Ana Cristina de Souza Vieira \\ Universidade Federal de Pernambuco (UFPE) \\ Maria Solange Guerra Rocha \\ Universidade Federal de Pernambuco (UFPE)
}

\author{
Judith Frances Head \\ University of Cape Town (UCT)
}

Isabel Maria Alçada Padez Cortesão Casimiro

Universidade Eduardo Mondlane (UEM)

\begin{abstract}
A epidemia de HIV/Aids e a ação do Estado. Diferenças entre Brasil, África do Sul e Moçambique Resumo: Este artigo discute a ação do Estado quanto à política de saúde para prevenção e tratamento de pessoas com HIV/Aids, foco de um estudo realizado entre 2011 e 2012 em três países do eixo sul-sul: Brasil, África do Sul e Moçambique, marcados por desigualdade de renda e pobreza, e por processos de cidadania em construção. Utiliza o método histórico-dialético para desenvolver uma pesquisa de tipo quantiqualitativo, com análise de dados secundários sobre a epidemia, a realidade socioeconômica e a política de saúde desses países. O trabalho de campo envolveu observação, grupos focais e entrevistas em unidades de saúde em Recife, Cape Town e Maputo. Conclui que a concretização do direito à saúde e à vida tem se tornado possível com o maior envolvimento do Estado na garantia de serviços e distribuição de antirretrovirais, com avanços mais significativos no Brasil que nos demais países.

Palavras-chave: HIV/Aids. Política de saúde. Direito à saúde.
\end{abstract}

The HIV/AIDS Epidemic and State Action, Differences between Brazil, South Africa and Mozambique Abstract: This article discusses the actions of the state in relation to health policy for the prevention and treatment of people with HIV/ AIDS, which was the focus of a study conducted in 2011 and 2012 that looked at three countries in the South-South axis: Brazil, South Africa and Mozambique, all of which are marked by income inequality and poverty, and by ongoing processes of the construction of citizenship. It used a dialectical-historical method to conduct a quantitative and qualitative study, which included an analysis of secondary data about epidemics, the socio-economic reality and healthcare policy in these countries. The fieldwork involved observation, focal groups and interviews at healthcare clinics in Recife, Cape Town and Maputo. It concludes that the concretization of the right to healthcare and to life has been made possible by the greater involvement of the state in guaranteeing services and distribution of antiretroviral medication, with more significant advances in Brazil than in the other countries.

Keywords: HIV/AIDS. Healthcare policy. Right to healthcare. 


\section{Introdução}

A política de saúde para prevenção e tratamento de pessoas com Vírus da Imunodeficiência Humana (HIV)/Síndrome da Imunodeficiência Adquirida (Aids) tem sido o foco de estudos desenvolvidos ao longo dos últimos anos por pesquisadoras de três diferentes países - Brasil, África do Sul e Moçambique. Em comum, esses países estão no eixo sul-sul, são marcados por desigualdades de renda, índices elevados de pobreza, condições de vida nem sempre dignas, cidadania em construção. Estão submetidos à orientação hegemônica do capitalismo financeiro nos dias atuais, debatendo-se com exigências neoliberais de privatização, desregulamentação de direitos, Estado mínimo em relação às políticas sociais que, entretanto, se expressam de formas e intensidades diversas em cada um.

Em relação à epidemia de HIV/Aids, o Brasil se diferencia dos demais, com uma prevalência de $0,6 \%$ na população entre 15 a 49 anos (MINISTÉRIO DA SAÚDE, 2013). Há 656.701 casos notificados de Aids

A Aids é uma epidemia que
expõe a exploração decorrente
das relações capitalistas, pois a
prevenção e a vivência com
HIV dependem em grande
medida, do acesso a serviços
de saúde, insumos,
informações, medicamentos.
Nessa perspectiva, o que
deveria ser direito universal à
saúde é convertido em espaços
de produção de lucros, num
processo de privatização que
tem se intensificado nas
últimas décadas.
desde o começo da epidemia em 1980, e estima-se que há 718 mil pessoas vivendo com HIV, sendo que 574.000 já diagnosticadas. Entretanto, os índices são mais elevados entre homens que fazem sexo com homens (HSH); usuários de drogas injetáveis (UD); profissionais de sexo (PS). A epidemia, apesar de estar decrescendo no Sudeste, vem crescendo em regiões mais pobres, como Norte e Nordeste e, entre mulheres.

A África do Sul tem uma epidemia generalizada de HIV, estabilizada a partir de 2006, com uma prevalência nacional entre mulheres grávidas em atendimento pré-natal de cerca de 30\% (REPUBLIC OF SOUTH AFRICA, 2012) e $15,9 \%$ na população entre 15 a 49 anos. As mulheres são maioria dentre as pessoas infectadas, expondo as desigualdades de gênero, em um país em que a poligamia é permitida, há altos índices de violência contra mulheres e a submissão da mulher expressa relações patriarcais fortemente enraizadas. O primeiro caso de Aids foi notificado em 1982 e hoje, passados 32 anos, há cerca de 5 milhões e 600 mil pessoas com HIV/Aids no país, o que levanta questionamentos sobre os motivos para esse imenso crescimento.

Em Moçambique há cerca de 2 milhões e 650 mil pessoas com HIV/Aids, uma epidemia também generalizada, que atinge $13,7 \%$ das mulheres em atenção pré-natal e 11,5\% da população na faixa de 15 a 49 anos (CASIMIRO et al., 2012). As mulheres são maioria dentre as pessoas com HIV/Aids, indicando a feminização e heterossexualização da epidemia ao longo de sua trajetória nesses países africanos.

A expansão do HIV/Aids nos três países indica também outro caminho da epidemia: a pauperização. Na África do Sul, a maioria das pessoas infectadas é negra e pobre, assim como a maioria da população do país, que tem $79,8 \%$ de Black Africans e apenas $8,7 \%$ de brancos (STATISTICS SOUTH AFRICA, 2013). Em Moçambique, a pobreza é a realidade de $54,7 \%$ da população, com 11,7 milhões de pessoas em situação de pobreza alimentar, com 99,5\% da população de origem negra (CASIMIRO et al., 2012). No Brasil, 62,4\% das pessoas com HIV/Aids tem escolaridade até Ensino Médio, o que é considerado indicador de uma condição socioeconômica entre baixa e média renda (MINISTÉRIO DA SAÚDE, 2013).

A Aids é uma epidemia que expõe a exploração decorrente das relações capitalistas, pois a prevenção e a vivência com HIV dependem em grande medida, do acesso a serviços de saúde, insumos, informações, medicamentos. Nessa perspectiva, o que deveria ser direito universal à saúde é convertido em espaços de produção de lucros, num processo de privatização que tem se intensificado nas últimas décadas. Revela, também, a manutenção da opressão, decorrente das relações patriarcais, na medida em que a prevenção é associada à normatização e controle da sexualidade, pela igreja, pelo Estado e pelas famílias.

A análise sobre os três países apresentou pontos comuns e distintos instigando uma aproximação ao que neles ocorre na tentativa de desvendar os rumos e as proporções distintas que a epidemia de HIV/Aids 
tomou. Não se trata de uma breve exposição sobre os mesmos, mas de uma tentativa de aproximação aos principais determinantes econômicos, culturais e políticos que os caracterizam, assim como em relação à epidemia de HIV/Aids. Esse exercício vai expor um importante vetor: a ação do Estado e os ritmos e rumos da epidemia em resposta à mobilização da sociedade em defesa de direitos. Parte-se da perspectiva que o Estado é responsável pela garantia de serviços sociais à população apesar de, em tempos neoliberais, haver uma tendência a sua desresponsabilização quanto à oferta desses serviços, repassados à esfera da sociedade para que concretize sua provisão.

Nesses países capitalistas existe uma desigualdade de renda própria desse modo de produção, no qual a riqueza cresce, mas não é dividida de forma justa e equitativa entre todos os trabalhadores. Portanto, entre aqueles que só têm sua força de trabalho para vender, o pauperismo se impõe como condição imprescindível à criação de valor. Convive-se com desiguais relações de poder às quais se agregam desigualdades entre mulheres e homens, pessoas de diferentes raças/etnias, pessoas com diferentes orientações sexuais, pessoas de diferentes gerações, enraizadas em tradições e culturas que geram preconceitos, opressões e permeiam as relações sociais. A epidemia de HIV/Aids, transmitida principalmente pela via sexual, expõe esses vários universos.

\section{Metodologia}

O estudo desenvolveu-se na perspectiva materialista histórico-dialética, optando-se por uma pesquisa de tipo quantiqualitativo. Foram utilizados dados secundários sobre a realidade socioeconômica dos três países estudados, a epidemia de HIV/Aids e a política de saúde, por meio dos quais se obteve informações para entender a trajetória da epidemia, sua dimensão, seus determinantes. O trabalho de campo envolveu procedimentos diversos. Foram realizadas três entrevistas com gestores de unidades de saúde estaduais para HIV/Aids em Recife, Brasil e a sistematização de uma apresentação do gestor estadual; sete entrevistas em Maputo, Moçambique; duas na Cidade do Cabo, África do Sul. Em Recife foram realizados dois grupos focais com homens com HIV/Aids, no Hospital Universitário Osvaldo Cruz (HUOC) e no Hospital Correia Picanço (HCP) e três grupos focais com mulheres, sendo dois nessas mesmas unidades de saúde e o terceiro no Hospital de Medicina Integral Fernando Figueira (IMIP). Em Maputo foram realizados seis grupos focais, sendo três femininos e três masculinos, em três unidades de saúde: Hospital José Macamo, Maternidade José Macamo e Centro de Saúde $1^{\circ}$ de Junho. Na Cidade do Cabo foram feitos três grupos focais, apenas um com homens, em clínicas que realizam tratamento de pessoas com HIV/Aids, em Milnerton e Philippi. Foram realizadas entrevistas em profundidade com pessoas com HIV/Aids nas unidades de saúde selecionadas em cada país, sendo três em Recife, seis em Maputo e três na Cidade do Cabo. A observação nas unidades de saúde onde foram realizados os grupos focais deu-se do cotidiano de atendimento. Os procedimentos respeitaram o constante na Declaração de Helsinki (1964, revisadas até 2008). O projeto no Brasil teve aprovação do Comitê Nacional de Ética, Registro no Sistema Nacional de Ética em Pesquisa (Sisnep) Folha de Rosto n. 445783, Registro no Comitê de Ética em Pesquisa do Centro de Ciências da Saúde, da Universidade Federal de Pernambuco (CEP/CCS/UFPE) n. 356/2011, obedecendo a todas as exigências éticas. Nos demais países, as equipes de pesquisa obtiveram aprovação das unidades de saúde para realização do trabalho de campo.

\section{Desigualdade e pobreza na África do Sul, Brasil e Moçambique}

África do Sul, Brasil e Moçambique viveram marcantes processos sociopolíticos nas últimas décadas. O Brasil teve uma feroz ditadura militar entre 1964 e 1985, objetivando a inserção do país, de forma subalterna, no sistema capitalista internacional, eliminando qualquer resistência a esse processo (no âmbito do Serviço Social a autocracia burguesa foi discutida de modo consistente por Netto, 1991). Com intensa mobilização social, no final dos anos 80 abriu-se um período de democratização, que culminou na Constituição de 1988.

Apesar de ter recebido os primeiros colonizadores em 1650, a África do Sul, só constituiu-se enquanto Estado em 1910. Construiu o apartheid em 1948, consolidado por meio da segregação de negros e privilegiamento da minoria branca. Esse regime passou a ser desmontado em 1990, em resposta a uma intensa luta nacional e a pressões internacionais que culminaram com a libertação de Nelson Mandela, eleito presidente em 1994. Havia a expectativa de eliminação da discriminação contra negros e coloured, de redução da pobreza e desigualdade, e de melhoria das condições dos negros. Em duas décadas de uma tentativa de construir direitos para todos, não apenas para a minoria branca, autores como Cameron (2013) consideram que apesar de haver mais liberdade e alguns avanços na justiça social, ainda há muito a ser feito para garantir direitos iguais para todos, assim como não se conseguiu reduzir a desigualdade social e a pobreza. 
A África do Sul de hoje vive uma intensa mobilização social, com protestos em várias partes do país reclamando a provisão de serviços públicos, como habitação, energia, saúde, educação, e com os trabalhadores, em meio a mais de $25 \%$ de desemprego, lutando por melhores salários e condições de trabalho. Mesmo sob um governo comandado por Jacob Zuma, presidente negro, de origem trabalhadora e envolvido em lutas anti-apartheid, o mundo presenciou uma manifestação trabalhista de mineiros da região de Marikana, em 2012, resultar em 44 mortes pela polícia. Atualmente, esse governo, reeleito em maio de 2014 para um segundo mandato, vem sendo alvo de críticas da oposição e dos cidadãos, diante do alto índice de desemprego, e da insuficiência de serviços públicos. Sustenta-se em uma coalizão originalmente de esquerda, formada pelo Congresso Nacional Africano (ANC), que capitaneou a luta contra o apartheid, pelo Partido Comunista da África do Sul (SACP) e pelo Congresso de Sindicatos Sul-Africanos (Cosatu).

Moçambique somente tornou-se independente de Portugal em 1975, após uma luta armada de libertação que durou 10 anos, encabeçada pela Frente de Libertação de Moçambique (Frelimo). Passado esse período, enfrentou 16 anos de guerra civil até 1992, que levou à luta seus cidadãos, divididos entre a Frelimo, de orientação socialista e a Resistência Nacional Moçambicana (Renamo), sendo esta apoiada pela África do Sul (ainda sob apartheid), Rodésia (atual Zimbabwe) e por outros países com interesses econômicos na região. Há uma minoria branca (menos de 1\%) de origem portuguesa, que assim como a população negra, dividiu-se entre os dois lados, tanto do movimento de libertação como do conflito civil que a ele seguiu-se. Moçambique também não conseguiu escapar de uma forte influência neoliberal, em seu movimento para enfrentar a crise do capital. Desde 2005 o país é presidido por Armando Guebuza, vencedor de duas eleições para presidência. Apesar da orientação socialista, assumida durante a luta de libertação e pelos governos eleitos a partir de então, impera uma orientação prómercado. Atualmente, os jornais estampam a corrupção existente no governo, o patrimonialismo, num país com alta dependência da cooperação internacional e grandes desafios para uma boa governança. Em 2013, a Renamo reiniciou ataques a forças militares e a civis em algumas regiões do país, numa tentativa de ganhar espaço político. Diante de um novo processo eleitoral em andamento, no início de fevereiro de 2014 foi assinado um acordo para cessar-fogo e negociar as reivindicações. A descoberta de minérios e gás abriu as portas do país para a exploração dessas riquezas por grupos estrangeiros, entre os quais, a Vale S.A., originária do Brasil.

Mundialmente, a onda neoliberal determinou a limitação ou o fracasso das tentativas de ampliar e garantir direitos sociais nesses países, embora seja possível verificar que o avanço neoliberal não chegou a esses três países com a mesma força. Na África do Sul corroeu as possibilidades de assegurar à população negra, maioria no país, o alcance das mesmas condições de vida garantidas à minoria branca. No Brasil, tem limitado o acesso a direitos sociais, apesar de o país apresentar indicadores de melhoria das condições de vida da população. A focalização da política de assistência social nos mais pobres, a privatização de serviços de saúde e a oferta limitada desses serviços, também voltados à população de mais baixa renda, quebram com a universalidade do direito. Em Moçambique, o crescimento econômico que promove uma nova elite rica, não tem garantido a redução da pobreza e o acesso aos serviços públicos.

O quadro 1 apresenta alguns indicadores estatísticos dos países. O Brasil se destaca pelo seu contingente populacional de 198.360 .493 habitantes, representando cerca de quatro vezes a população sul-africana e oito vezes a moçambicana. Nesses países as mulheres são maioria em relação aos homens, ainda que por pequena margem - 50,42\% na África do Sul, 50,82\% no Brasil e 51,65 em Moçambique, único deles em que a população rural $(68,57 \%$ ) é maior que a urbana. O Brasil tem $84,9 \%$ de sua população vivendo em área urbana, enquanto a África do Sul tem $62,44 \%$, mostrando que as aglomerações urbanas vêm concentrando crescentemente a população. Nelas estão a maioria das pessoas com HIV/Aids. Nesse país, o intenso movimento migratório campo-cidade, iniciado após o apartheid, expõe a opção dos governos por uma forma de desenvolvimento econômico em que a industrialização, a mineração e os serviços predominam sobre a atividade rural, e que, ao mesmo tempo concentra os investimentos em infraestrutura nas áreas escolhidas pelo capital privado para realizar empreendimentos, o que exige, também, disponibilidade de mão de obra.

Viver na área urbana ou rural acaba por significar maior ou menor acesso a serviços públicos, o que se expressa em dados como o acesso de apenas $47 \%$ da população à água potável em Moçambique, ou a taxa de alfabetização de apenas $46,2 \%$, sendo necessário destacar que entre as mulheres a taxa de analfabetismo é de 64,1\%. É preciso considerar também, em relação a Moçambique e África do Sul, a diversidade de línguas que dificulta a comunicação e a alfabetização.

A taxa bruta de natalidade vem decrescendo no Brasil (15 por mil) e na África do Sul (21 por mil), mas ainda é alta em Moçambique (38 nascimentos por mil). O número de mortes também é mais elevado nesse país e na África do Sul, sendo que ambos têm a mesma taxa de mortalidade (15 por mil), enquanto no Brasil, essa taxa é de 6 por mil. A esperança de vida ao nascer no Brasil está na média de 73,8 anos, em 53,4 na África do Sul e em 50,7 em Moçambique. Esses últimos indicadores mostram fundamentalmente o acesso reduzido a políticas públicas, determinando a limitação da vida, assim como expõem a epidemia de HIV/Aids. 


\section{Quadro 1 - Dados populacionais e econômicos da África do Sul, Brasil e Moçambique}

\begin{tabular}{|l|c|c|c|c|}
\hline Indicadores & & África do Sul & Brasil & Moçambique \\
\hline Habitantes & $\mathbf{2 0 1 2}$ & 50.738 .255 & 198.360 .493 & 24.275 .186 \\
\hline População feminina & $\mathbf{2 0 1 2}$ & 25.583 .916 & 100.805 .716 & 12.539 .032 \\
\hline População urbana & $\mathbf{2 0 1 2}$ & $62,44 \%$ & $84.9 \%$ & $31.43 \%$ \\
\hline População rural & $\mathbf{2 0 1 2}$ & $37,56 \%$ & $15,1 \%$ & $68,57 \%$ \\
\hline Taxa bruta natalidade & $\mathbf{2 0 1 0}$ & 21 por mil & 15 por mil & 38 por mil \\
\hline Taxa bruta mortalidade & $\mathbf{2 0 1 0}$ & 15 por mil & 6 por mil & 15 por mil \\
\hline Índice de Gini (2000-2010) & & 0,631 & 0,547 & 0,457 \\
\hline IDH & $\mathbf{2 0 1 3}$ & 0,629 & 0,730 & 0,327 \\
\hline IDH-D (ajustado à desigualdade) & & Não disponível & 0,531 & 0,220 \\
\hline Esperança de vida ao nascer & & 53,4 anos & 73,8 anos & 50,7 anos \\
\hline Total PIB (billion US\$) & $\mathbf{2 0 1 1}$ & 408.237 & 2.476 .651 & 12.823 \\
\hline PIB per capita (US\$) & $\mathbf{2 0 1 3}$ & 9.678 & 10.278 & 861 \\
\hline Taxa de desemprego & & 25,6 & $6 \%$ & $22,5 \%$ \\
\hline
\end{tabular}

Fonte: Dados obtidos em: <http://www.ibge.gov.br/paisesat/>. Acesso em: 16 jul. 2013, sendo exceções 1) Coeficiente de Gini de rendimentos, e o PIB per capita, obtidos no PNUD (2013). Disponível em: http://www.un.cv/files/ HDR2013\%20Report\%20Portuguese.pdf. Acesso em: 4 Ago. 2014. 2) Taxa de Desemprego, com dados da África do Sul obtidos em matéria disponível em: <http://www.tradingeconomics.com/south-africa/unemployment-rate> citando como fonte Statistics South Africa (órgão oficial), veiculada em 30 jul. 2013; dados do Brasil obtidos em: <http://agenciabrasil.ebc.com.br/noticia/2013-07-24/taxade-desemprego-fica-em-6-em-junho-diz-ibge>, com base no IBGE, em matéria veiculada em 24 jul. 2013; dados de Moçambique obtidos em: <http://www.verdade.co.mz/economia/37028-mocambique-com-taxa-de-desemprego-de-225> a partir de informação veiculada pelo Diretor-geral do Instituto Nacional de Emprego e Formação Profissional (INEFP) do Ministério do Trabalho, em 24 maio 2013.

O Índice de Desenvolvimento Humano - IDH 2012 (PNUD, 2013) expressa condições de vida, considerando renda, saúde e educação, apontando que Moçambique tem as piores condições, situando-se no antepenúltimo lugar entre 186 países, com índice de 0,327. A África do Sul situa-se no $121^{\circ}$ lugar, com IDH 0,629 , quase o dobro do moçambicano, e o Brasil, com 0,730, em $85^{\circ}$ lugar. Ao se considerar esse mesmo índice ajustado à desigualdade, esses países têm uma significativa redução de sua posição, quando o IDH-D passa a ser de 0,220 em Moçambique e 0,531 no Brasil, não havendo dado disponível para a África do Sul. É preciso referir, entretanto, que o IDH expressa uma média que esconde a precariedade da vida nas favelas brasileiras e moçambicanas, assim como nas townships, as favelas sul-africanas distantes dos centros urbanos, verdadeiros guetos, cujas condições são completamente diversas daquelas encontradas nos bairros de maioria branca, muitos dos quais parecem mais paraísos europeus.

Apesar de sua posição em relação ao IDH, Moçambique tem a menor desigualdade de renda entre os países focalizados, como mostra o Índice de Gini de 0,457, em contraposição a 0,547 do Brasil e 0,631 da África do Sul, situado entre os dez países mais desiguais do mundo. Até alguns anos atrás o Brasil também se situava nesse conjunto, escapando desse grupo na década de 2000, em razão de algumas ações governamentais, dentre as quais, a política de valorização do salário mínimo, a redução do desemprego, a existência de programas de transferência de renda.

Se a pobreza vem se reduzindo no Brasil, ainda que sem mudar significativamente a condição de desigualdade, na África do Sul ocorre um processo em que a pobreza e a desigualdade se acentuam. Moçambique vive uma situação difícil, apesar da expectativa de mudança:

O crescimento económico de Moçambique, nos últimos anos, tem sido dos mais elevados do mundo, com uma taxa de crescimento média de $8 \%$, nos últimos 15 anos. O rendimento per capita de Moçambique é ainda de somente $\$ 440$, por ano, fazendo com que seja um dos países mais pobres do mundo, onde $55 \%$ da população vive com menos do que $\$ 1$ por dia. A economia está baseada essencialmente na agricultura de pequena escala, embora isto esteja a mudar, com a recente descoberta de níveis significativos de recursos minerais e gás natural, no norte do país (REPÚBLICA DE MOÇAMBIQUE, 2013, p. 9).

O PIB total desses países, que expressa a riqueza produzida, é extremamente diferente: o brasileiro, de U\$2.476.651 contém 193 vezes o moçambicano e seis vezes o sul-africano, enquanto o PIB per capita, ou seja, o que caberia em média a cada cidadão anualmente se essa riqueza produzida fosse distribuída equitativamente 
é, respectivamente, da ordem de US\$ 10.278; US\$ 861 e US\$ 9.978. Diante do PIB total e per capita de Moçambique, portanto, percebe-se que os recursos gerados são muito mais limitados que aqueles produzidos nos demais países, implicando em grandes diferenças em relação ao que é disponibilizado pelo setor público para realização de obras de infraestrutura e para políticas públicas.

\section{HIV/Aids, seus rumos e o Estado}

A epidemia de HIV/Aids nesses países deve ser pensada como produto da realidade de desigualdade e pobreza, das lutas sociais pela garantia de direitos, das respostas do Estado diante de demandas sociais ou de sua ausência. A África do Sul tem o maior contingente de pessoas com HIV no mundo. Segundo Susser (2009, p. 71-73),

O sistema de saúde sob o apartheid era segregador e inadequado e os estágios iniciais da epidemia de Aids foram caracterizados pela negligência e superlotação de hospitais públicos e clínicas [...]. O regime de apartheid na África do Sul, previsivelmente, negligenciou a propagação da Aids entre a população negra [...] [Somente após a libertação de Mandela] dados epidemiológicos sobre Aids entre a população Africana começaram a ser coletados. Em 1990, o primeiro conjunto de dados mostrou uma taxa de infecção de $0,8^{1}$.

Durante o apartheid, havia diferentes políticas de saúde para negros, brancos e demais grupos populacionais, comandadas por 15 departamentos de saúde ao nível nacional, com orçamentos diferenciados, para delimitar as ações de saúde para cada segmento, mas os brancos tinham acesso a melhores unidades de saúde e serviços. O governo de Nelson Mandela, a partir de 1994, desenvolveu um esforço para desconstruir a legislação do apartheid, elaborar uma nova Constituição e estender benefícios sociais à população negra, num momento em que a principal preocupação era garantir a estabilidade nacional. Esse objetivo suplantou a preocupação com a expansão da epidemia de HIV, num momento em que, internacionalmente, o neoliberalismo se fortalecia e imprimia a ideia de menos Estado, a redução de políticas sociais e seu direcionamento apenas aos mais pobres. Enquanto crescia a epidemia de Aids, em 1996 "o governo sul-africano instituiu um massivo ajustamento estrutural e políticas de privatização através do programa Growth, Employment and Redistribution, que veio a ser conhecido como GEAR ${ }^{2 "}$ (SUSSER, 2009, p. 90).

No governo que sucedeu Mandela, Thabo Mbeki, houve um retrocesso na atenção à epidemia, partindo do próprio presidente um movimento de negação quanto à ligação entre HIV e Aids, o que gerou a limitação de ações governamentais. Com isso, os caminhos do HIV foram definidos: "Ainda em 1990, a prevalência estimada de infecção por HIV na África do Sul era de menos de 1\%. Estes números cresceram dramaticamente em meados da década de 90, alcançando 22,8\% em 1998" (POSEL, 2006, p. 40). Enquanto a nova democracia concentrava-se na Constituição e na redução da desigualdade racial, o crescimento da Aids mobilizava segmentos da sociedade, com forte atuação da Treatment Action Campaign (TAC), para a garantia de acesso aos antirretrovirais, em um processo bem sucedido somente em 2010, quando o governo adotou a política de garantir universalmente antirretrovirais através de mais de 4.000 clínicas públicas e privadas, já com Jacob Zuma como presidente.

O sistema de saúde sul-africano também mudou, com a extinção dos múltiplos departamentos de saúde e a criação em 2012 do Seguro Nacional de Saúde (National Health Insurance - NHI) como um sistema de financiamento para garantir que todos os cidadãos sul-africanos e os residentes legalizados de longa permanência sejam providos por cuidados essenciais de saúde, independentemente do status de trabalhador formal (REPUBLIC OF SOUTH AFRICA, 2014). Esse sistema, ainda em fase de implantação, exige uma contrapartida financeira de quem ganha acima de certo patamar de renda. São ofertados serviços em diferentes níveis, desde a atenção primária aos níveis altamente especializados de cuidados, mas com ênfase na prevenção e promoção da saúde.

Em Moçambique, o Serviço Nacional de Saúde não alcança 42\% do território nacional (CASIMIRO et al., 2012), o que deixa uma população de maioria pobre sem resposta para suas necessidades de saúde. No mesmo ano do primeiro caso de Aids, 1986, foi criada a Comissão Nacional da Sida (nome adotado em Moçambique para a Aids), nos moldes propostos pela Organização Mundial de Saúde (OMS). Em 1988 foi criado o primeiro programa de controle de Infecções Sexualmente Transmissíveis (IST), HIV e Aids. Em 2003 iniciou-se a distribuição de antirretrovirais, que atualmente beneficia apenas $51,7 \%$ dos que precisam e em 2004 iniciou-se um programa nacional de enfrentamento da transmissão vertical. O governo moçambicano elaborou três Planos Estratégicos Nacionais, desde 2000, mas apesar da resposta governamental à Aids, o atual Plano de Aceleração da Resposta ao HIV e Sida 2013-2015, afirma que: 
A epidemia do HIV, em Moçambique, continua a ameaçar o futuro social e económico do país. Em alguns locais do país, mais de um quarto dos adultos estão infectados. A prevalência nacional do HIV é a oitava mais alta do mundo. Ao longo da década passada, Moçambique realizou avanços encorajadores na resposta à epidemia, mas com uma estimativa de 1,4 milhões de pessoas vivendo com HIV/SIDA e 120.000 novas infecções por ano, a resposta ao HIV deve ser fortalecida e acelerada (REPÚBLICA DE MOÇAMBIQUE, 2013, p. 6).

O Sistema Nacional de Saúde em Mocambique, criado em 1991, é um serviço misto em que coexistem os setores público, privado e comunitário, que se complementam e colaboram entre si. Numa tentativa de evitar a discriminação, os dois hospitais-dia abertos em 1996 e 1997 para pessoas com HIV/Aids foram fechados. Hoje, elas são atendidas em serviços abertos a todas as pessoas. Entretanto, o sistema de saúde público tem limites em decorrência dos recursos escassos:

Actualmente, Moçambique é altamente dependente do Apoio Oficial ao Desenvolvimento e do financiamento de doadores, sendo que $22 \%$ do Orçamento Geral do Estado e 59\% das despesas do sector da saúde são provenientes de fundos de doadores ou da cooperação bilateral. A despesa pública na saúde foi de $5.8 \%$ do GDP, em 2011, enquanto as despesas na saúde per capita, em 2012, foram de \$26.1 por ano. Apesar das enormes limitações de recursos existentes em Moçambique, o GRM [Governo da República de Moçambique] tem conseguido manter os serviços essenciais de saúde gratuitos (REPÚBLICA DE MOÇAMBIQUE, 2013, p. 9).

O Brasil difere desses países em relação à garantia do direito à saúde. O Sistema Único de Saúde (SUS) criado em 1988 e regulamentado em 1990, propõe-se a garantir a saúde enquanto direito em caráter universal em todo o país, sem contribuição financeira. Este é um diferencial, pois ainda que a implementação do SUS tenha limitações e problemas, a garantia legal existe e há uma mobilização na sociedade para sua permanência.

Depois de mais de uma década de desenvolvimento de ações com recursos do Banco Mundial, em 2010 os gastos públicos com a saúde no Brasil para enfrentamento do HIV/Aids foram de US\$1.329.000.000 exclusivamente de fontes governamentais. Desse total, 70,2\% foram gastos com ações de tratamento e $19,9 \%$ com prevenção (BRAZILIAN MINISTRY OF HEALTH, 2012). O gasto total com saúde em HIV/Aids de Moçambique foi de US\$146.420.694, mas o governo arcou apenas com 3\%, enquanto 96\% são oriundos de organismos e parceiros internacionais e 1\% do setor privado (REPUBLIC OF MOZAMBIQUE, 2012). A África do Sul gastou no enfrentamento do HIV/Aids e tuberculose, US\$1.616.533.224 dos quais 75\% são de responsabilidade governamental e 16,4\% de organismos internacionais, mantendo o maior programa mundial de distribuição de antirretrovirais, mas que só em 2010 foi iniciado como política de Estado. Comparativamente, apesar do menor valor nominal de gastos em relação à África do Sul, o Brasil como tem menos pessoas com HIV, tem um maior investimento na epidemia.

Dados do Programa Conjunto das Nações Unidas sobre HIV/Aids - Unaids (2012) e outras fontes possibilitam uma visão sobre HIV/Aids. A estimativa de novos casos (incidência) de Aids em países do continente africano é muito alta: entre os sul-africanos é de 380.000 e de 130.000 entre os moçambicanos. No Brasil ocorreram apenas 39.185 novos casos em 2011, conforme mostra o quadro 2, pouco mais de 10\% que na África do Sul.

\section{Quadro 2 - Dados sobre HIV/Aids na África do Sul, Brasil e Moçambique}

\begin{tabular}{|l|c|r|r|r}
\hline Indicadores & Ano dado & \multicolumn{1}{c}{ África do Sul } & \multicolumn{1}{c}{ Brasil } & \multicolumn{1}{c}{ Moçambique } \\
\hline Estimativa de prevalência de & 2001 & $2001-15,90$ & $2001-0,4 \%$ & $2001-9,7 \%$ \\
HIV (pop. 15 a 49 anos) & 2011 & $2011-17,30 \%$ & $2011-0,3 \%$ & $2011-11,3 \%$ \\
\hline Estimativa de pessoas vivendo & 2001 & 4.400 .000 & 450.000 & 850.0001. \\
com HIV & 2011 & 5.600 .000 & 490.000 & 400.000 \\
\hline Estimativa de novas infecções & 2001 & 610.000 & $31.064^{*}$ & 140.000 \\
por HIV & 2011 & 380.000 & $39.185^{* *}$ & 130.000 \\
\hline Óbitos por Aids & 2011 & $200.259^{* * *}$ & $12.140^{* *}$ & 74.000 \\
& 2012 & $191.620^{* * *}$ & $11.896^{* *}$ & 600.000 \\
\hline Pessoas precisam ARV & 2011 & 2.600 .000 & 300.000 & 273.561 \\
Pessoas em ARV & 2011 & 1.702 .060 & 215.676 & Mulher $-8,2$ \\
\hline Percentagem de jovens entre 15 a & 2011 & Mulher - 11,9\% & Mulher $-0,10$ & Homem $-2,80$ \\
\hline 24 anos vivendo com HIV & & Homem - 5,3\% & Homem - 0,10 \\
\hline
\end{tabular}

Fonte: UNAIDS (2012), exceto *Boletim Epidemiológico (2011),**Boletim Epidemiológico (2013), ***Statistics South Africa (2013). 
Nos três países, a distribuição do HIV pelo território é variável, sendo maior nas áreas onde há concentração de empreendimentos econômicos. Para Susser (2009, p. 3), "o vírus da Aids acompanha a grande circulação de trabalhadores precipitada pela constante mudança global de investimentos". Na África do Sul, marcada por um processo de migração em busca do trabalho, pode-se traçar o crescimento da Aids por meio do acompanhamento de movimentos migratórios.

A estimativa de mortes por Aids foi reduzida no Brasil desde a introdução da terapia antirretroviral em 1996, extensiva a todos os que têm indicação de uso, e fornecida gratuitamente por cerca de 700 unidades de saúde no território nacional. A partir de 2013, o governo brasileiro estabeleceu novos parâmetros para indicação de antirretrovirais, propondo que desde a detecção do HIV seja feito o tratamento, por considerar que esse procedimento contribui para a redução de novos casos da doença. Entretanto, o estabelecimento desses novos parâmetros não se fez acompanhar de indicação de ampliação dos serviços nem de profissionais de saúde, num quadro em que os usuários já reclamam da demora para a marcação de consultas, a dificuldade de acesso a exames e tratamentos especializados. Na África do Sul há mais de 4.000 clínicas fornecendo antirretrovirais, compondo o maior programa mundial de distribuição de medicamentos para Aids, e que ainda não consegue atender todos os que necessitam, dada a dimensão da epidemia no país. A terapia antirretroviral é fornecida a 65,46\% dos que precisam (quadro 2). No Brasil, em torno de 72\% das pessoas infectadas têm acesso à terapia, enquanto em Moçambique, somente 45,6\% das pessoas com Aids têm acesso aos antirretrovirais. Em 2011 ocorreram 200.259 mortes na África do Sul, correspondendo a 34,6\% dos óbitos no país, ou seja, 1/3 dos óbitos no país aconteceram em decorrência de Aids. Em 2012, foram 191.620 óbitos, indicando a redução de mortes por Aids como consequência da distribuição de antirretrovirais. Nos últimos 10 anos, o percentual mais alto de óbitos ocorreu em 2005, com 344.657 pessoas, representando 47,7\% das mortes no país. No Brasil, os dados do Ministério da Saúde (2013) apontam a ocorrência de 11.896 mortes por Aids como causa básica em 2013, enquanto desde 1980 até 2012 são contabilizados ao todo 265.698 óbitos, pouco mais que o total de um só ano na África do Sul. Em Moçambique a estimativa de mortes por Aids era de $74.000 \mathrm{em}$ 2011, expondo a ainda limitada distribuição de antirretrovirais.

Em relação às mulheres, se no início da epidemia nos três países, elas eram minoritariamente atingidas, ao longo das décadas foram sendo infectadas através de relações heterossexuais. Mulheres jovens se tornaram as maiores vítimas da epidemia. Na faixa etária entre 15 e 24 anos, as mulheres são mais atingidas pelo HIV na África do Sul - 11,9\% de mulheres, em comparação a 5,3\% de homens. Em Moçambique, a relação mulher/homem é mais acentuada: para 8,3\% de mulheres jovens há apenas 2,8\% de homens jovens atingidos. Apenas no Brasil, o percentual de mulheres e homens jovens se equipara - 0,10\% para homens e mulheres nessa faixa etária. Nos países africanos, o sexo intergeracional motivado pela necessidade de sobrevivência; padrões culturais pelos quais cabe ao pai-tio-irmão escolher com quem uma menina vai casar, podendo haver pagamento pelo noivo; a iniciação sexual de meninas por homens mais velhos; a poligamia; a violência contra a mulher contribuem para a disseminação da epidemia entre mulheres jovens. Mia Couto, escritor moçambicano, escreveu sobre o seu país:

A nossa sociedade vive em permanente e generalizado estado de violência contra a mulher. Essa violência é silenciosa (eu preferia dizer que é silenciada) por razões de um alargado compadrio machista. Os níveis de agressão doméstica são enormes, a violência contra as viúvas já foi reportada em livro, a violência contra as mulheres idosas acusadas de feitiçaria e, por isso, punidas e estigmatizadas [...] as mulheres dos quinze aos 24 anos são duas vezes mais susceptíveis de serem contaminadas pela Sida do que os rapazes. Estes números todos sugerem uma silenciosa mutilação nacional, um estado permanente de guerra contra nós mesmos. Esta é a conclusão que podemos sugerir, a fechar: um país em que as mulheres só podem ser a sua metade está condenado a ter apenas metade do seu futuro (COUTO, 2011, p. 137-138).

O que dizer sobre pobreza em relação às pessoas com HIV/Aids? No Brasil a escolaridade tem sido usada "como variável proxi de situação socioeconômica, e o fenômeno de pauperização tem sido caracterizado pelo aumento da proporção de casos de Aids com baixa escolaridade" (BRITO, 2006). Dados do Boletim Epidemiológico 2013 indicam a escolaridade de pessoas com HIV/Aids no país: são 64,9\% de pessoas com até 11 anos de escolaridade, incorporando aí os analfabetos, que representam apenas $3 \%$. O baixo percentual de pessoas vivendo com HIV/Aids, com curso superior completo, especialmente de mulheres $(6,9 \%)$, significa que estão sujeitos a uma renda menor, à pobreza (BOLETIM EPIDEMIOLÓGICO, 2013).

Se pensarmos nos indicadores apresentados no quadro 1, destacando desemprego, veremos que este também pode ser utilizado para pensar a pobreza. A África do Sul, considerada a potência econômica da região tem taxa de 25,6\% em relação ao desemprego, superando Moçambique, cuja taxa é de 22,5\%, ou seja, 1/4 da população sul-africana e mais de $1 / 5$ da moçambicana não tem trabalho, o que significa que não tem como 
garantir sua sobrevivência. Não há dados sobre como se comporta o desemprego entre as pessoas com HIV, mas é de supor que as pessoas infectadas, nem sempre com acesso a tratamento antirretroviral, devem ter maiores dificuldades em obter emprego, pois precisam ir a consultas, os medicamentos causam efeitos colaterais, há preconceito e discriminação.

Uma questão a ser enfrentada para pessoas vivendo com HIV/Aids é a falta de programas de apoio assistencial, que garantam acesso a alimentação, habitação, transporte, para as pessoas que não conseguem se inserir no mercado de trabalho em função da doença e do estigma a ela vinculado. Não existem programas específicos para as pessoas com HIV/Aids no Brasil nem em Moçambique. Contudo, diferente de Moçambique, no Brasil trabalhadores formais com HIV/Aids têm o auxílio-doença e a aposentadoria, assim como acesso a recursos do Fundo de Garantia do Tempo de Serviço (FGTS), enquanto alguns estados garantem acesso gratuito a transporte público. Na África do Sul há benefícios assistenciais que podem ser acessados pelas pessoas com HIV/Aids, mas não configuram um direito. Como afirmaram algumas mulheres com HIV, participantes dos grupos focais tanto no Brasil como na África do Sul, "não vivemos só de antirretrovirais".

\section{Considerações finais}

O enfrentamento da epidemia no sentido de reduzir a infecção em homens e mulheres exige diferentes ações, entre as quais o fortalecimento das políticas sociais. O crescimento exponencial da epidemia na África do Sul e em Moçambique, só se explica pela ausência do Estado. No Brasil, o crescimento da epidemia não teve a mesma expansão, e a ação do governo foi fundamental, pressionado e em estreita articulação com redes de movimentos sociais e ONGs, garantindo ainda nos anos 1990, acesso aos antirretrovirais. Em 2012, vetos conservadores do Governo Federal brasileiro a campanhas e material educativo para jovens e profissionais do sexo geraram um manifesto assinado por mais de 400 instituições e profissionais indicando uma violação dos direitos humanos, anteriormente afirmados diante de movimentos sociais e ONGs. Questiona-se que a epidemia de Aids esteja sob controle no Brasil, apontando que há um esgotamento da capacidade de intervir e evitar que um número maior de pessoas se infecte e morra em decorrência da Aids. Afirma-se que a capacidade de estados e municípios para responder à epidemia deve ser reforçada, além de se reconhecer a necessidade de mecanismos inovadores para garantir a sustentabilidade institucional das ONGs que trabalham com Aids.

No Brasil, serviços não especializados para HIV/Aids, abertos a toda a população recebem alta demanda para consultas e exames, gerando filas e demora no atendimento. Foram ouvidas histórias de discriminação nesses serviços, em que as pessoas com HIV/Aids são atendidas apenas no final do expediente, além de ouvir comentários discriminatórios sobre o estado sorológico. Na África do Sul, problemas mencionados pelo/as entrevistado/as contribuem para afastar dos serviços as pessoas com HIV/Aids: filas, algumas segregando quem tem HIV/Aids, longa espera, insuficiência de profissionais médicos, com atendimento nas clínicas feito por enfermeiras, queixas quanto à equipe de apoio, que com frequência trata grosseiramente os usuários.

Na realidade de pessoas vivendo com HIV, identifica-se a ausência do Estado, maior em Moçambique, na África do Sul, mas também no Brasil. Essa ausência se manifesta de diferentes formas. A adoção da orientação neoliberal limita ações de planejamento estatal, reduz recursos, políticas sociais, programas e ações. A mão invisível do mercado não conseguiu realizar o bem comum nas nações africanas, não conseguiu controlar o crescimento da epidemia de HIV, infectando mais de $10 \%$ da população, já imersa na pobreza em decorrência de anos de apartheid na África do Sul ou da colonização predatória e da luta por projetos de sociedade (esquerda x direita) em Moçambique. As relações de classe somam-se à questão racial, numa imbricação que fere a maioria do povo africano.

Em 1990, um representante sindical do National Union of Mineworks (NUM), da África do Sul, declarou: "Está claro, que meramente abordar a sexualidade das pessoas não vai resolver o problema [Aids].

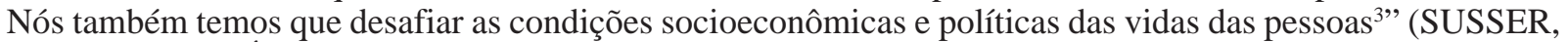
2009, p. 77). A África do Sul demorou a se engajar nesses desafios, e isso custou inúmeras vidas, em sua maioria de mulheres. Moçambique mostrou um compromisso com a epidemia, entretanto, não consegue garantir efetivos recursos para responder ao imenso custo da epidemia, carregando essa responsabilidade. O Brasil mostrou a capacidade de enfrentamento da epidemia garantindo universal acesso aos antirretrovirais, mas para isso foi fundamental a existência de um sistema de saúde universal, público, gratuito, formalizado pela Constituição de 1988 e uma legislação própria. Mas ainda enfrenta o desafio do crescimento da epidemia em algumas regiões, com expansão entre mulheres e a população mais pobre, assim como no interior do país. Nos três países sente-se a ausência de estratégias para as mudanças de comportamento e a transformação das profundas raízes do nó que ata patriarcado-capitalismo-racismo-sexismo, que limita iniciativas e não rompe as amarras da tradição e cultura, assim como da herança colonialista dos países pesquisados. 


\section{Referências}

BRAZILIAN MINISTRY HEALTH. Health Surveillance Secretariat. Department of STD, Aids and Viral Hepatitis. Progress Report on the Brazilian Response to HIV/AIDS (2010-2011). Brazil, 2012.

BRITO, A. M. A evolução e distribuição social da doença no Brasil. Com Ciência. Revista Eletrônica de Jornalismo Científico. SBPC: Campinas, SP, n. 76, 2006. Disponível em: 〈http://comciencia.br/comciencia/?section=8\&edicao=13\&id=116>. Acesso em: 4 ago. 2013.

BOLETIM EPIDEMIOLÓGICO HIV. Aids. Brasília, DF, Ano II, n. 1, dezembro de 2013. Disponível em: <http://www.aids.gov.br/ sites/default/files/anexos/publicacao/2013/55559/_p_boletim_2013_internet_pdf_p_51315.pdf>. Acesso em: 10 mar. 2014.

CAMERON, E. Two decades of having rights. And a future worth fighting for. The Big Issue 2013/2014 Collector's Edition. Cape Town, 2013.

CASIMIRO, I. et al. Relatório de pesquisa do Projecto de Pesquisa "Desafio do Sida nas suas Dimensões Socioeconomicas, Culturais e Políticas no Brasil, África do Sul e Moçambique 2011-2012”. Maputo, novembro de 2012.

COUTO, M. E se Obama fosse africano? E outras interinvenções. Ensaios. São Paulo: Companhia das Letras, 2011.

NETTO, J. P. Ditadura e Serviço Social. Uma análise do Serviço Social no Brasil pós-64. São Paulo: Cortez, 1996.

POSEL, D. A controvérsia sobre aids na África do Sul: marcas da política de vida e morte no Pós-Apartheid. Afro-Asia, 34, p. 39-66. Salvador: UFBA, 2006. Disponível em: <http://www.redalyc.org/articulo.oa?id=77003402>. Acesso em: 10 mar. 2014.

REPUBLIC OF MOZAMBIQUE. Global AIDS Response Progress Report for the Period 2010 - 2011. Mozambique: National Aids Council, 2012.

REPUBLIC OF SOUTH AFRICA. Global Aids Response Progress Report 2012. South Africa, 2012.

fev. 2014.

Ministry of Health. National Health Insurance. 2014. Disponível em: 〈http://www.health.gov.za/nhi.php〉. Acesso em: 19

REPÚBLICA DE MOÇAMBIQUE. Ministério da Saúde. Plano de Aceleração da Resposta ao HIV e Sida. Moçambique 2013-2015;

Maputo, 2013.

STATISTICS SOUTH AFRICA. Mid-Year Population Estimates. South Africa: Statistics South Africa, 2013. Disponível em: <http:// beta2.statssa.gov.za>. Acesso em: 24 mar. 2014.

SUSSER, I. AIDS, Sex and Culture. Global Politics and Survival in Southern Africa. Malden (USA): Wiley-Blackwell, 2009.

UNAIDS - United Nations Programme on HIV/Aids. Global Report: Unaids Report on the Global Aids Epidemic. 2012. Disponível em: <http://www.unaids.org/en/media/unaids/contentassets/documents/epidemiology/2012/gr2012/20121120_unaids_global_report_2012_ -with_annexes_en.pdf $>$. Acesso em: 4 ago. 2013.

\section{Notas}

1 Tradução livre. No original: "The health system under apartheid was segregated and inadequate and the early stages of AIDS epidemic were characterized by neglect and overcrowding."

2 Tradução livre. No original: "The South African government instituted massive structural adjustment and privatization policies through the Growth, Employment and Redistribution policy that came to be known as GEAR".

3 Tradução livre. No texto original: "It is clear, however, that merely addressing people's sexuality will not solve the problem. We also have to challenge the socioeconomic and political conditions of people."

\section{Ana Cristina de Souza Vieira}

anacvieira12@gmail.com

Doutora em Serviço Social pela Pontifícia Universidade Católica de São Paulo (PUC-SP)

Docente do Departamento de Serviço Social e da Pós-Graduação em Serviço Social, da Universidade Federal de Pernambuco (UFPE)

\section{UFPE}

Rua Prof. Moraes Rego, 1235

Cidade Universitária

Recife - Pernambuco - Brasil

CEP: 50670-901 


\section{Maria Solange Guerra Rocha}

msolgrocha@gmail.com

Doutora em Serviço Social pela Universidade Federal de Pernambuco (UFPE)

Pesquisadora associada do Departamento de Sociologia da University of Cape Town (UCT)

\section{University of Cape Town}

Private Bag X3

Rondebosch

7701

South Africa

\section{Judith Frances Head}

judith.head@uct.ac.za

Pós-Doutora em Sociologia pela University of Durham (UK)

Docente do Departamento de Sociologia da University of Cape Town (UCT)

\section{University of Cape Town}

Private Bag X3

Rondebosch

7701

South Africa

\section{Isabel Maria Alçada Padez Cortesão Casimiro}

isabelmaria.casimiro@gmail.com

Doutora em Sociologia pela Universidade de Coimbra

Professora do Centro de Estudos Africanos da Universidade Eduardo Mondlane (UEM)

\section{Universidade Eduardo Mondlane}

Centro de Estudos Africanos

Campus Universitário Principal, Caixa Postal 1993

Maputo - Moçambique 